in a similar dose in the same vehicle by the same route. The two groups were comparable in terms of gestation, birth weight, age on admission to the trial, Apgar score at 1 and 5 mins, ambient oxygen requirements, arterial $\mathrm{PaO}_{2}$ and $\mathrm{PaCO}_{2}$, ac:d-base status, calculated alveolar-arterial oxygen gradients, and in plasma corticosteroid concentrations. All received identical management. An attempt was made to keep the $\mathrm{PaO}_{2}$ between 60 and $100 \mathrm{~mm} \mathrm{Hg}$. When it fell below $50 \mathrm{~mm} \mathrm{Hg}$ in $100 \%$ oxygen, or the Paco: rose above $70 \mathrm{~mm} \mathrm{Hg}$, assisted mechanical ventilation was instituted. Both groups had a similar course, with no differences in ambient $\mathrm{O}_{2}$ requirement, $\mathrm{PaO}_{2}, \mathrm{Paco}_{2}$, acid-base status, or alveolar arterial oxygen gradients.

The treated group did not benefit from the high hydrocortisone concentrations in serum achieved by treatment; 11 required assisted ventilation, with 6 deaths. In the placebo group 9 required ventilation, with 7 deaths. From this trial it would thus appear that, if corticosteroids are to be used in the modification or prevention of respiratory distress syndrome, the postnatal period is too late.

A number of questions are raised by these studies. A larger trial would be necessary to determine whether the antenatal administration of betamethasone is advantageous when the pregnancy has proceeded beyond 32 weeks gestation. It would be important to explore the possibility that corticosteroids have an adverse effect when the placenta may be damaged by vascular disease, lest the higher mortality noted in infants born to mothers who had pre-eclampsia is in any way attributable to this form of treatment. The dosage of corticosteroids used in this trial was an empirical one, and improved therapeutic regimens based on a better understanding of the mode of action of glucocorticoids would seem a distinct possibility. At present, however, the mode of action of the glucocorticoids in causing lung maturation remains to be determined. The plasma cortisol and cortisone concentration in infants with respiratory distress syndrome before beginning treatment was significantly higher than in premature control infants. ${ }^{3}$ Their use in pharmaceutical doses, it is suggested, may enhance release of surfactant or increase its synthesis. ${ }^{11}$ Thyroxin ${ }^{12}$ in the experimental animal and heroin, both experimentally ${ }^{13}$ and clinically, ${ }^{14}$ have similar effects, indicating that production of surfactant can be enhanced by a variety of seemingly unrelated agents. It is noteworthy that Liggins and R. N. Howie ${ }^{2}$ found no consistent change in the lecithin/sphingomyelin ratio of amniotic fluid before and after betamethasone therapy, though this ratio is considered to be an index of pulmonary surfactant production. $^{15}$ It seems possible, therefore, that other possible modes of action of corticosteroids may have to be considered before a more rational therapy can be advised.

1 Scopes, J., in Recent Advances in Paediatrics, 4th Edn., p. 89, ed. D. Gairdner and D. Hull. London, Churchill, 1971.

2 Liggins, G. G., and Howie, R. N., Pediatrics, 1972, 50, 515.

Baden, M., et al., Pediatrics, 1972, 50, 526

- Liggins, G. G., Fournal of Endocrinology, 1969, 45, 515.

5 Brumley, G. W., et al., fournal of Clinical Investigation, 1969, 46, 863

- Delemos, R. A., Shermeta, D. W., Knelson, J. H., Kotas, R., Avery, M. E. American Review of Respiratory Diseases, 1970, 102, 459.

7 Reynolds, E. O. R., Robertson, N. R. C., and Wrigglesworth, J. S., Pediatrics, 1968, 42, 758.

8 Naeye, R. L., Harcke, H. T., and Blanc, W. A., Pediatrics, 1971, 47, 650.

' Naeye, R. L., Harcke, H. T., and Blanc, W. A.,, Pediatrics,

10 Haddad, H., Hsia, D., Gellis, S., Pediatrics, 1956, 17, 204.

10 Altman, H., South African Medical Fournal, 1965, 39, 746.

11 Farrell, P., and Zachman, R. D., Pediatric Research, 1972, 6, 337.

12 Redding, R. A., Douglas, W. H. J., and Stein, M., Science, 1972, 175, 994

13 Glass, L., Rajegowda, K. K., and Evans, H. E., Lancet, 1971, 2, 685 . Research, 1972, 6, 335 .

15 Whitfield, C. R., Chan, W. H., Sproule, W. B., and Stewart, A. D., British Medical fournal, 1972, $2,85$.

\section{Bacteriology of Impetigo}

Bacterial skin infections are still common despite improved standards of hygiene and the therapeutic use of antibiotics and other powerful bactericidal preparations. In general practice up to $10 \%$ of all patients may require treatment for staphylococcal infections each year, the incidence being highest in the first six months of life, adolescence, and early adult life. Impetigo is particularly common. It is due to superficial infection with staphylococci or streptococci and in a high proportion of patients to infection with both organisms.

Micrococci are part of the normal skin flora, but Staphylococcus pyogenes, an important pathogen, is rarely commensal on normal skin and Streptococcus viridans in the mouth only. But asymptomatic skin-carrier rates for pathogenic staphylococci are high. If repeated sampling is carried out, in particular of the skin surrounding body cavities such as the nares, the carrier rate may approach $100 \%$. The nares and perineum are among the commonest carrier sites, and most people are at least intermittent carriers. ${ }^{1}$ Carriage of pathogenic staphylococci is also common in the scalp. ${ }^{2}$ That the carrier rate is higher in urban than in rural communities $^{3}$ cannot cause surprise, but genetic factors also play an important part in the nasal carrier rate of staphylococci. The rate was found to be higher in Caucasians than in similarly exposed negroes, ${ }^{4}$ and $\mathrm{H}$. Nierman ${ }^{5}$ reported that while impetigo affected simultaneously $92 \%$ of monozygotic twins only $29.5 \%$ of dizygotic twins were affected after otherwise similar exposures.

Patients with staphylococcal skin infections can usually be shown to carry identical staphylococci in their noses, on their perineum, and on other areas of clinically normal skin. ${ }^{1}$ Since these people are often chronic nasal carriers of staphylococci they present problems of clinical management as well as a community hazard. There is no evidence that asymptomatic chronic carriers of staphylococci have developed protective immunity against them. Minor trauma may rapidly produce an infected skin lesion, from which the same phage type of staphylococcus is cultured as from the nose. However, it can be assumed that nonspecific physical and chemical factors prevent clinical infection and that some measure of immunological protection is also being developed. For disorders interfering with any of these mechanisms, such as endocrinopathies or immunological incompetence, whether occurring naturally or induced by therapy, may give rise to or may indeed present clinically as recurrent skin infection.

Staphylococci differ in their pathogenicity to skin. Most skin infections are found to be due to six phage types, with types $80,80 / 81$, and 71 predominating. Staphylococci of the phage type $80 / 81$, as well as producing widespread and frequent epidemics of wound infection in hospitals and impetigo and boils in hospital staff, are also usually resistant to the most widely used antibiotics. Infections with them require immediate and vigorous treatment, including systemic antibiotics, to which they are susceptible. The risks of staphylococcal wound infection on a surgical ward need not be emphasized further, but impetigo may be associated also with nephritogenic streptococci. ${ }^{6}$

The realization that there may be a correlation between the high incidence of acute glomerulonephritis in the tropics and subtropics and impetigo, which is nearly always streptococcal in those regions, is fairly recent. ${ }^{7}$ The nephritogenic streptococcus, belonging to the M-type and known as type 
49, has been found to be associated with nephritis in the U.S.A., Trinidad, Czechoslovakia, and Holland. ${ }^{8}$

A group of Egyptian workers have recently published the bacteriological findings in 131 children with impetigo, mostly aged 1-5 years.9 Staph. aureus was isolated from 114 cases $(87 \%)$. It was the only pathogenic organism in $40.5 \%$ and occurred together with streptococci in $36 \%$. In $9 \%$ it was found together with a diphtheroid. Phage-typing of Staph.aureus was done in only 25 patients, most of whom had type 80. Pure cultures of beta-haemolytic streptococci were obtained from $9 \%$. Not all were grouped and typed and unfortunately no information was given whether any possessed $M$ antigen.

In the same study a haemolytic diphtheroid was isolated from 7 patients, including one child in whom neither staphylococci nor streptococci were found. This organism was found to produce necrotic abscesses when injected into rabbits. Intraperitoneal injections into male guinea-pigs killed the animals in two to four days. While the Egyptian authors found, like many European and American workers, that staphylococci with or without Str. pyogenes were predominant in impetigo, their finding of a seemingly pathogenic corynebacterium, resembling $C$.pyogenes, in impetigo appears to be a new finding. The authors suggest the possibility of an animal source of this infection, since most children came from a rural area. In only one patient was no other pathogen than the haemolytic diphtheroid isolated, and it seems advisable to await confirmation of this finding before adding this organism to the very short list of pathogenic organisms in a condition which has been extensively studied by bacteriologists since Radcliffe Crocker recognized its infectious nature in 1881 .

1 Williams, R. E. O., British fournal of Dermatology, 1969, 81, Supplement

1, 33.
2 Summers, M. M., Lynch, P. F., and Black, T., fournal of Clinical Pathology, 1965, 18, 13.

Pathology, 1965, 18, 13.
3 Schubert, Ö., Zeitschrift für Hygiene und Infektions-krankheiten, medizinische Mikrobiologie, Immunologie und Virologie, 1959, 132, 465

4 Millian, S. J., Baldwin, J. N., Rheins, M. S., and Weisser, H. H., American fournal of Public Health, 1960, 50, 791.

5 Nierman, H., Zwillings Dermatologie. Berlin, Springer, 1964.

Markowitz, M., Bruton, D., Kuttner, A. G., and Leighton, E. C., Pediatrics, 1965, 35, 393.

'Parker, M. T., British fournal of Dermatology, 1969, 81, Supplement 1, 37.

${ }^{3}$ Maxted, W. R., Fraser, C. A. M., and Parker, M. T., Lancet, 1967, 1, 691.

- El Zawahry, M., Abdel Aziz, A., and Soliman, M., British fournal of Dermatology, 1972, 87, 420.

\section{Mental Symptoms and Parkinsonism}

James Parkinson's "An Essay on the Shaking Palsy"1 assured for him an everlasting place among medicine's immortals. Published in 1817, this slender monograph described for the first time in lucid, elegant prose a disease which is "of a nature highly afflictive," whose essential symptoms are tremor and paralysis. In the light of scientific development since Parkinson's time much of his thinking in terms of aetiology, pathology, and treatment, which he concedes are "opinions and not facts," can be discarded. Indeed, with the evolution of psychiatry as a specialty in its own right even the final statement of his definitionnamely, that of "the senses and intellects being uninjured" -has been seriously questioned.

The American Handbook of Psychiatry noted in 19592: "Although it is usually stated that a mental change is not characteristic of parkinsonism, depression and bradyphrenia are common reactions in this syndrome complex." Subsequently a series of publications, mainly in the U.S.A., have further challenged Parkinson's dictum. The latest of these is a paper by G. G. Celesia and W. M. Wanamaker ${ }^{3}$ from Wisconsin University, in which they report on the psychiatric disturbances of 153 patients, 62 women and 91 men, suffering from (idiopathic) Parkinson's disease. It is important to note their finding that every type of Parkinson's syndrome, whether postencephalitic, arteriosclerotic, or toxic, produces similar psychiatric sequelae.

What is surprising in this investigation is the high incidence of disturbances-much higher, in fact, than any so far reported. The authors divide them into three categories, dementia, depression, and acute psychotic disorders. Of the 61 patients $(40 \%)$ diagnosed as suffering from dementia 24 were classified as mild, 26 as moderate, and 11 as severe. The mental impairment increases, the authors say, with the progression of the disease, and the more severe the motor disability the worse is the dementia. They argue, logically, that the pathological process responsible for the motor dysfunction is also responsible for the dementia. None of the patients, it is emphasized, was on levodopa when first evaluated, but most were on anticholinergic drugs. Ten were on no drugs at all.

Fifty seven $(37 \%)$ had symptoms of depression or had been depressed in the year preceding their initial evaluation. The incidence of depression was higher in females than in males. There was no relationship between the severity of the motor disability and the prevalence of depression or its grade. Depression could occur at any stage of the disease and was not related to the age of the patient or the duration of the disease. Here again the effect of drugs on the course the disease takes is discussed. In this series the prevalence of depression in patients not treated with levodopa was $37 \%$, while in those receiving the drug it was $24 \%$, a small but statistically significant difference. Furthermore, $1.5 \%$ of patients receiving levodopa developed hypomania, a symptom not reported as occurring spontaneously in patients with Parkinsonism. It is suggested, therefore, that not only does levodopa not cause depression but that it may help to prevent it.

The third category of mental disturbance, acute psychotic episodes, comprised attacks in which the patient experienced hallucinations, distortion of reality, and various degrees of behavioural disorder. These episodes the authors firmly attribute to the drugs used in treatment. Twenty patients $(13 \%)$ became so afflicted, and of the drugs incriminated eight were related to levodopa, four were anticholinergics, and six were other drugs such as barbiturates and minor tranauillizers. What is particularly noteworthy is that 15 of the 20 patients had varving degrees of dementia.

Though not specifically the subiect of this paper, what needs to be considered is the possible damage to the brains of countless thousands of patients suffering from a variety of psychiatric disorders who are receiving psychotropic drugs, sometimes in heroic doses, both in and out of mental hospitals in all parts of the world. Drug-induced Parkinsonlike disease is now a commonolace in psychiatric practice. Nor is it necessarily reversible bv the withdrawal of the drugs or the prescribing of anti-Parkinsonism medication. This irreversible condition has come to be known as tardive dyskinesia. G. E. Crane stated in an imbortant symoosium ${ }^{4}$ on this subject, "Tardive dyskinesia was practically unknown only a few years ago, but at present manifestations consistent 